\title{
Enhanced Operant Extinction and Prefrontal Excitability in a Mouse Model of Angelman Syndrome
}

\author{
(DD Michael S. Sidorov, ${ }^{1,2,3}$ Matthew C. Judson, ${ }^{1,2,3}$ Hyojin Kim, ${ }^{1,2,3}$ Marie Rougie, ${ }^{1,2,3}$ Alejandra I. Ferrer, ${ }^{1,2,3}$ \\ Viktoriya D. Nikolova, ${ }^{2,4}$ Natallia V. Riddick, ${ }^{2,4}$ Sheryl S. Moy, ${ }^{2,4}$ and ${ }^{\circledR B}$ Benjamin D. Philpot ${ }^{1,2,3}$ \\ ${ }^{1}$ Department of Cell Biology \& Physiology, ${ }^{2}$ Carolina Institute for Developmental Disabilities, ${ }^{3}$ Neuroscience Center, and ${ }^{4}$ Department of Psychiatry, \\ University of North Carolina, Chapel Hill, North Carolina 27599
}

\begin{abstract}
Angelman syndrome (AS), a neurodevelopmental disorder associated with intellectual disability, is caused by loss of maternal allele expression of UBE3A in neurons. Mouse models of AS faithfully recapitulate disease phenotypes across multiple domains, including behavior. Yet in AS, there has been only limited study of behaviors encoded by the prefrontal cortex, a region broadly involved in executive function and cognition. Because cognitive impairment is a core feature of AS, it is critical to develop behavioral readouts of prefrontal circuit function in AS mouse models. One such readout is behavioral extinction, which has been well described mechanistically and relies upon prefrontal circuits in rodents. Here we report exaggerated operant extinction in male AS model mice, concomitant with enhanced excitability in medial prefrontal neurons from male and female AS model mice. Abnormal behavior was specific to operant extinction, as two other prefrontally dependent tasks (cued fear extinction and visuospatial discrimination) were largely normal in AS model mice. Inducible deletion of Ube3a during adulthood was not sufficient to drive abnormal extinction, supporting the hypothesis that there is an early critical period for development of cognitive phenotypes in AS. This work represents the first formal experimental analysis of prefrontal circuit function in AS, and identifies operant extinction as a useful experimental paradigm for modeling cognitive aspects of AS in mice.
\end{abstract}

Key words: Angelman syndrome; excitability; extinction; prefrontal cortex; UBE3A

Significance Statement

Prefrontal cortex encodes "high-level" cognitive processes. Thus, understanding prefrontal function is critical in neurodevelopmental disorders where cognitive impairment is highly penetrant. Angelman syndrome is a neurodevelopmental disorder associated with speech and motor impairments, an outwardly happy demeanor, and intellectual disability. We describe a behavioral phenotype in a mouse model of Angelman syndrome and related abnormalities in prefrontal cortex function. We hypothesize that robust and reliable prefrontally encoded behavior may be used to model cognitive impairments in Angelman syndrome.

\section{Introduction}

Angelman syndrome (AS) is a neurodevelopmental disorder defined by cognitive impairment, speech and motor abnormalities, and a unique behavioral profile that includes hypersociability. In

Received Sept. 29, 2017; revised Jan. 24, 2018; accepted Jan. 27, 2018.

Author contributions: M.S.S., M.C.J., S.S.M., and B.D.P. designed research;M.S.S., M.C.J., H.K., M.R., A.I.F., V.D.N., N.V.R., and S.S.M. performed research; M.S.S., M.C.J., H.K., M.R., A.I.F., V.D.N., N.V.R., and S.S.M. analyzed data; M.S.S. and B.D.P. wrote the paper.

This work was supported by NINDS R01NS085093 to B.D.P., NICHD T32HD040127 to M.S.S., NINDS F32NS077686 to M.C.J., and Simons Foundation SFARI 433935 to A.I.F; confocal imaging was supported by NINDS Center Grant P30NS045892 and NICHD U54HD079124; and the behavioral core was supported by NICHD U54HD079124 to S.S.M. We thank Ellen Clark for maintaining animal colonies and Luis Quintanilla for assisting with behavioral studies.

The authors declare no competing financial interests.

Correspondence should be addressed to Dr. Benjamin D. Philpot, University of North Carolina, 115 Mason Farm Road, Campus Box 7545, Chapel Hill, NC 27599. E-mail: bphilpot@med.unc.edu.

A. I. Ferrer's present address: Department of Cell Biology, Physiology, and Neuroscience, Rutgers, The State University of New Jersey, Newark, NJ 07103.

DOI:10.1523/JNEUROSCI.2828-17.2018

Copyright $\odot 2018$ the authors $\quad 0270-6474 / 18 / 382671-12 \$ 15.00 / 0$
$>80 \%$ of cases, AS is also associated with seizures, microcephaly, and abnormal EEG patterns (Thibert et al., 2013). AS is caused by mutations causing loss of expression of the maternal copy of UBE3A in neurons (Kishino et al., 1997; Bird, 2014) and has been modeled preclinically using Ube3a maternal null mice (Ube3a $a^{m-1 p^{+}}$; AS model mice; Jiang et al., 1998). Reliably conserved features of AS model mice include enhanced seizure susceptibility, microcephaly, EEG abnormalities, and locomotor deficits (Jiang et al., 1998; Miura et al., 2002; van Woerden et al., 2007; Heck et al., 2008; Huang et al., 2013; Mandel-Brehm et al., 2015; SilvaSantos et al., 2015; Judson et al., 2016, 2017; Born et al., 2017; Sidorov et al., 2017). Cognitive impairment has proven more difficult to model in mice. Here we sought to characterize behaviors in AS model mice that engage known prefrontal circuits. In humans, prefrontal cortex is broadly involved in executive function, and dysfunction in prefrontal circuits likely contributes to cognitive impairments in neurodevelop- 
mental disorders such as AS (O'Hearn et al., 2008; Yuan and Raz, 2014).

Behavioral extinction is an active learning process (Bouton, 2004; de Carvalho Myskiw et al., 2015) that engages infralimbic (IL) medial prefrontal cortex (mPFC) in rodents (Herry et al., 1999; Quirk et al., 2000; Milad and Quirk, 2002; Peters et al., 2009). After learning an association between a cue and a shock (fear conditioning) or learning that an action results in a reward (operant acquisition), extinction learning occurs when there is a decrease in the contingency between the conditioned and unconditioned stimulus, or between the action and the reward outcome. Extinction learning is associated with increased in vivo firing of neurons, c-fos activation, and protein synthesis in IL (Milad and Quirk, 2002; Santini et al., 2004; Knapska and Maren, 2009). Inhibition of IL impairs extinction; this finding has been demonstrated using lesion studies, chemical infusions, and both optogenetic and chemogenetic manipulations (Morgan et al., 1993; Quirk et al., 2000; Sierra-Mercado et al., 2006; Knapska and Maren, 2009; Laurent and Westbrook, 2009; Sparta et al., 2014; Do-Monte et al., 2015; Augur et al., 2016; Kim et al., 2016). Moreover, extinction directly facilitates increases in the excitability of IL neurons (Santini et al., 2008; Cruz et al., 2014), and studies using associative fear extinction, operant drug seeking, and conditioned place preference suggest that IL uses similar enhancements in neuronal firing to encode extinction across modalities (Ovari and Leri, 2008; Peters et al., 2008, 2009; Kaplan et al., 2011; Millan et al., 2011).

Here we measured operant extinction in AS model mice. We used the same extinction protocol previously used to reveal enhanced operant extinction in a mouse model of Fragile X syndrome (Sidorov et al., 2014), a single-gene disorder that has phenotypic overlap with AS. We report that operant extinction is similarly enhanced in AS model mice, and that IL neurons from AS model mice show increased excitability. Inducible deletion of Ube $3 a$ during adulthood was sufficient to modulate excitability but was not sufficient to drive enhanced extinction, supporting the idea that there is an early critical period for the development of AS-like behavioral phenotypes (Silva-Santos et al., 2015). Surprisingly, enhanced extinction in AS mice was restricted to operant tests and did not generalize to associative fear. In addition, visuospatial discrimination, another prefrontally encoded behavior that is impaired in Fragile X model mice (Krueger et al., 2011), was only modestly altered in AS model mice. Overall, this work establishes operant extinction as a simple and reliable readout of cognitive impairment in AS model mice that may be driven by prefrontal circuit dysfunction.

\section{Materials and Methods}

Animals. The Institutional Animal Care and Use Committee of the University of North Carolina at Chapel Hill approved all animal protocols. We group-housed mice on a $12 \mathrm{~h}$ light/dark cycle with ad libitum access to food and water, except where noted during food restriction. Experimenters performed all studies using littermate controls and blind to genotype and treatment. For all behavioral experiments, we used male mice; we used male and female mice in equal ratios for electrophysiological experiments. Jackson Laboratories provided AS (016590) and inducible CAG-Cre ${ }^{\mathrm{ERT}}$ mouse lines (004682). Our laboratory, with the UNC Animal Models Core facility, generated the floxed Ube3a mouse line $\left(U b e 3 a^{F L X / p^{+}}\right)$(Judson et al., 2016). We maintained all lines on a congenic C57BL/6J background. We generated experimental AS model mice $\left(U b e 3 a^{m-/ p+}\right)$ and wild-type littermates (Ube $\left.3 a^{m+/ p+}\right)$ by crossing female Ube $3 a^{m+/ p-}$ and male Ube $3 a^{m+/ p+}$ breeders. We generated experimental inducible deletion mice (FLX; Ube $3 a^{F L X / p+}:: C A G-C r e^{E R T}$ ) and wild-type littermates (WT; Ube $3 a^{m+p+}:: C A G-C r e^{E R T}$ ) by crossing fe- male $U b e 3 a^{m+/ F L X}$ and male homozygous $C A G-C r e^{E R T}$ breeders. We used 2- to 4-month-old adult mice for all experiments.

Operant behavioral systems. We performed all operant behavioral experiments (Figs. 1, 3, 6) using modular operant conditioning chambers (MED Associates, ENV-307W). These chambers had five available nosepoke apertures on one wall and a food delivery magazine on the opposite wall. A house light over the food magazine illuminated the chamber. Stimulus lights inside the nose-poke apertures were individually controlled to provide operant cues, as noted.

Operant acquisition and extinction. We used previously established methods (Sidorov et al., 2014) with minor modifications to measure operant acquisition and extinction (Fig. 1). We food restricted mice for the duration of experiments ( $1.5 \mathrm{~h}$ of unrestricted feeding followed testing). We performed all experiments during the light phase at the same time each day. We covered three nose-poke apertures, leaving two open for testing (Fig. 1B). First, we trained mice (two $10 \mathrm{~min}$ sessions on consecutive days) to receive a food reward (20 mg dustless precision pellets, Bio-Serv) every time they nose-poked into the food magazine ["magazine training" (MAG)]. During operant acquisition (ACQ; 15 min sessions), we illuminated one aperture at a time, and mice received a reward only after a nose-poke into the illuminated ("cued") aperture. We defined a "non-cued" response as a nose-poke into the non-illuminated aperture, and a "trial" as the receipt of reward following one or more cued responses. Trials were self-initiated by the mice; therefore, the number of trials per session was open-ended. We presented the light cue in the same aperture during every trial across days, while randomizing cue location (left or right aperture) across mice. To encourage responding, we delivered rewards on a fixed FR1 schedule for the first 10 rewards, then on a variable VR2 schedule for the following rewards. We also "primed" mice: on the first $2 \mathrm{~d}$ of training, we placed one food pellet inside both the cued and non-cued aperture. Subsequently, we primed mice for $1 \mathrm{~d}$ following training days on which mice completed $<5$ trials. Mice needed to complete $>15$ trials within a session, and $>75 \%$ cued response rate [cued responses/(cued + non-cued responses)], over 5 consecutive days to meet criteria for successful operant acquisition. For conditional deletion experiments, mice also underwent $5 \mathrm{~d}$ of retention testing with reward present following Ube3a deletion (see Fig. 3A). Immediately following acquisition (or retention, as noted), mice underwent $3-5 \mathrm{~d}$ of extinction training, where the light cue was presented without reward (Figs. 1, 3). Where noted, we performed $1 \mathrm{~d}$ of probe testing (no reward) 4 weeks following extinction and $1 \mathrm{~d}$ of reinstatement testing (with reward) the day after probe testing (Fig. 1). Where noted, we normalized cued and non-cued responses to the group average of the last $5 \mathrm{~d}$ of acquisition.

Cued fear extinction. We evaluated mice for extinction of conditioned fear using a near-infrared image tracking system (MED Associates), using a procedure incorporating the following phases (see Fig. $5 A$ ): Day 1 , training; Day 2, a test for cue-dependent learning ("acquisition"); Days 3-5, three consecutive, once-daily tests for extinction; Day 8, a final extinction test. On Day 1, we placed each mouse in the test chamber, contained in a sound-attenuating box, and we allowed them to explore for $2 \mathrm{~min}$. We then exposed the mice to a $30 \mathrm{~s}$ tone $(75 \mathrm{~dB})$, followed by a $2 \mathrm{~s}$ scrambled foot shock $(0.4 \mathrm{~mA})$. Mice received two additional shocktone pairings, with $80 \mathrm{~s}$ between each pairing. On Day 2, we evaluated mice for associative learning of the auditory cue in a $5 \mathrm{~min}$ session. Here we modified the conditioning chambers using a Plexiglas insert to change the wall and floor surface, and we added a novel odor (dilute vanilla flavoring) to the sound-attenuating box to change the olfactory context. We placed mice in the modified chamber and allowed them to explore. After $2 \mathrm{~min}$, we presented the acoustic stimulus (a $75 \mathrm{~dB}$ tone) for a $3 \mathrm{~min}$ period during which the image tracking system recorded levels of freezing, which we compared with freezing exhibited before presentation of the tone. For each extinction test, we placed mice into the modified conditioning chamber, recording baseline responses without the cue for $2 \mathrm{~min}$. We then exposed mice to six repeated presentations of the tone ( $30 \mathrm{~s}, 75 \mathrm{~dB})$, with $30 \mathrm{~s}$ between each exposure.

Visuospatial discrimination. We used previously established methods (Krueger et al., 2011; Sidorov et al., 2014) with minor modifications to measure visuospatial discrimination. The procedure had the following 

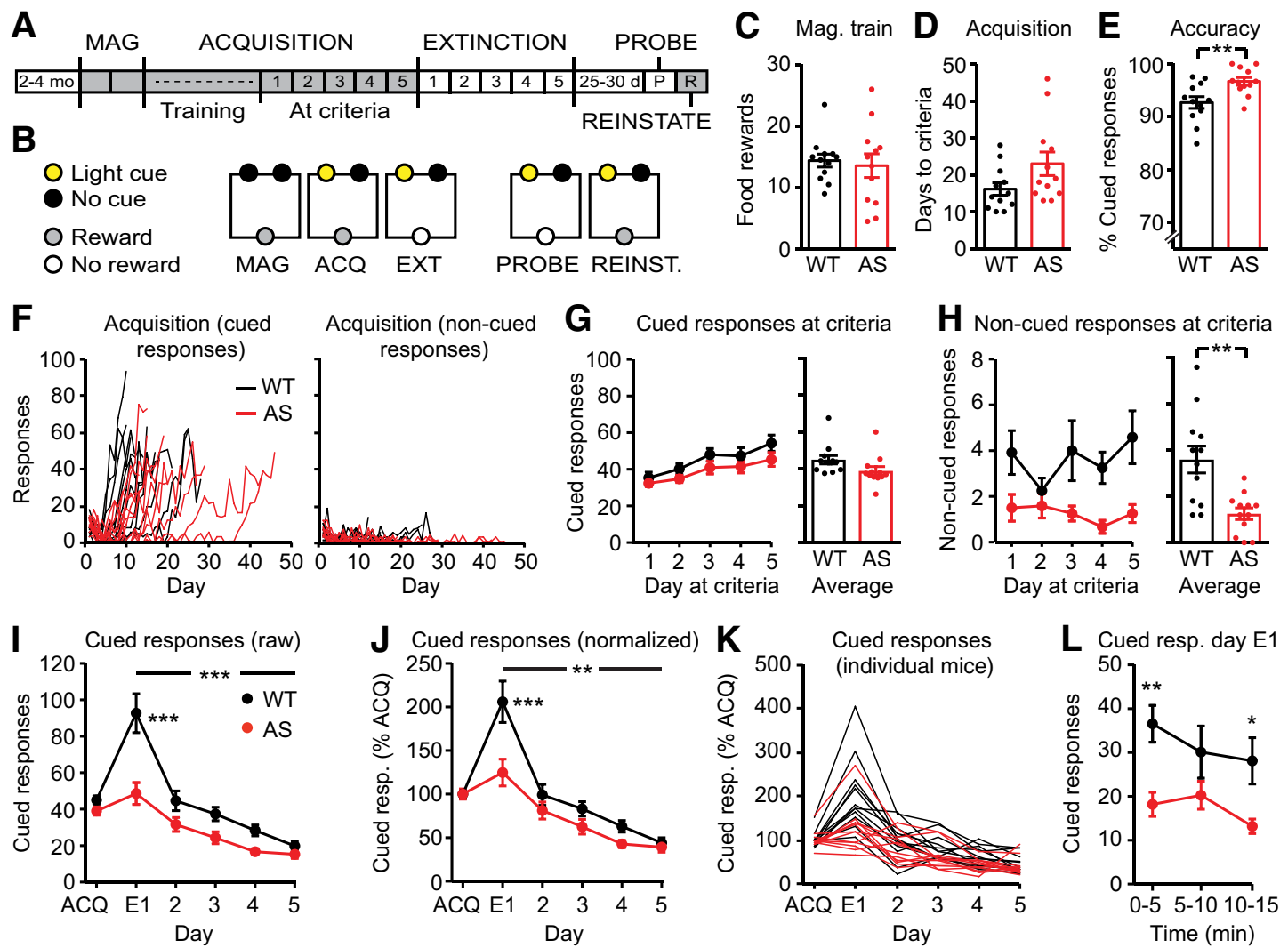

M Cued resp. day E1

$\mathbf{N}$ Cued resp. day ACQ5

O Non-cued responses (raw)
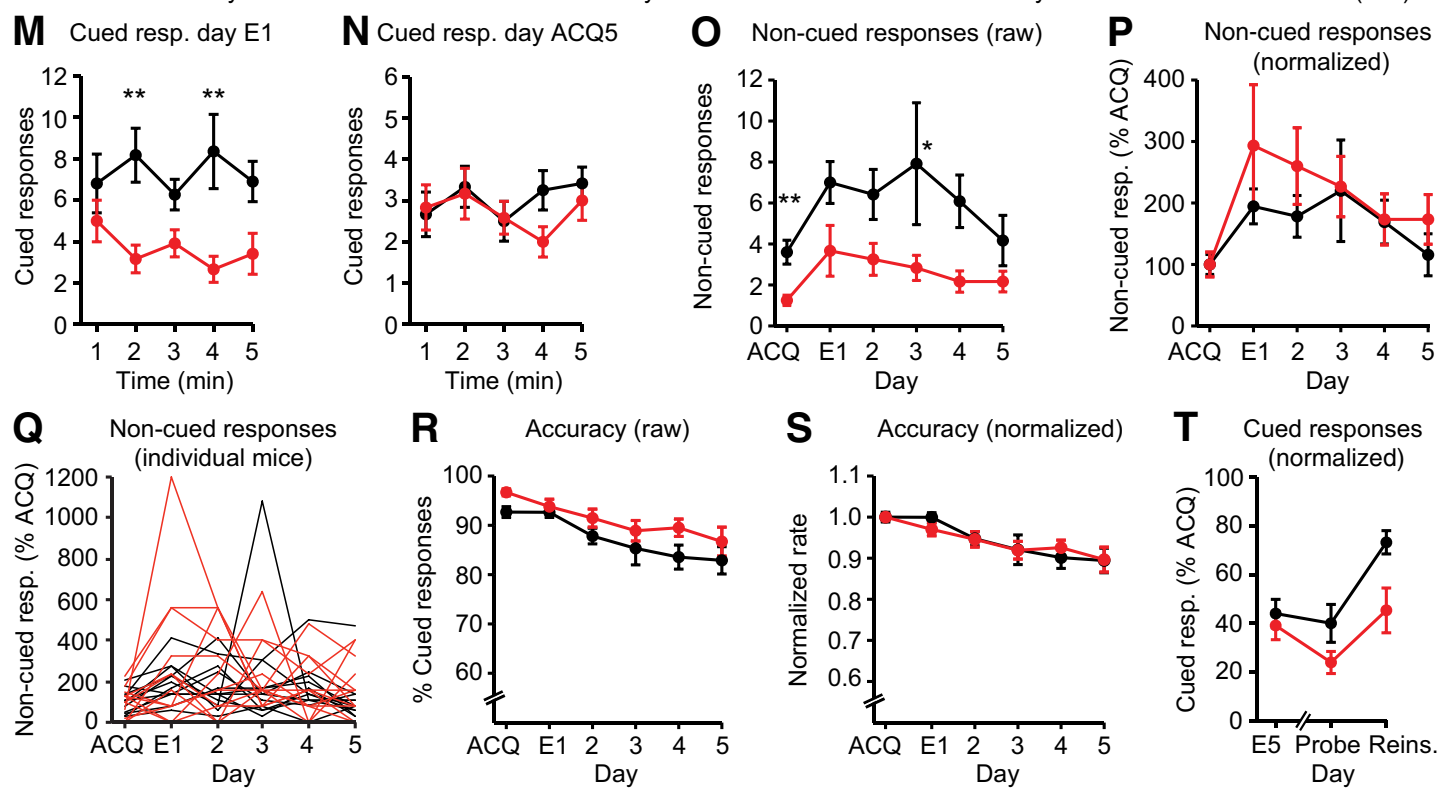

Figure 1. Exaggerated operant extinction in AS model mice. $A$, Experimental timeline shows $M A G, A C Q, E X T$, and probe and reinstatement tests. Gray indicates the presence of food reward (MAG, $A C Q$, reinstatement) and white indicates the absence of reward (EXT, probe). $\boldsymbol{B}$, Behavioral chambers contained a food magazine and two nose-poke apertures. Schematics indicate the presence (yellow) or absence (black) of light cue and the presence (gray) or absence (white) of reward during testing phases. C, Magazine training and (D) operant acquisition were normal in AS mice. WT: $n=12 ; \mathrm{AS}: n=12 . E$, Response accuracy (proportion of responses in the cued aperture) was increased in AS mice. $F$, Learning curves illustrate cued responses (left) and non-cued responses (right) across acquisition. $\mathbf{G}$, Cued and $(\boldsymbol{H})$ non-cued responses at criteria. Left, All $5 \mathrm{~d}$ at criteria. Right, Average of $5 \mathrm{~d}$. $\boldsymbol{I}$, Operant extinction was exaggerated in AS mice (asterisks indicate genotype $\times$ time interaction and post hoc test). $\boldsymbol{J}$, Normalization of cued responses during extinction to the group means of cued responses during the last $5 \mathrm{~d}$ of acquisition. $\boldsymbol{K}$, Normalized cued responses for all subjects. L, Exaggerated extinction in AS mice emerged rapidly on day E1 (asterisks indicate post hoc tests). $\boldsymbol{M}$, Cued responses during the first 5 min of day E1 and (N) day ACQ5. $\mathbf{O}, \mathrm{AS}$ mice had fewer non-cued responses during acquisition and this phenotype persisted during extinction. $\boldsymbol{P}$, Non-cued responses, normalized to acquisition, were normal in AS mice. $\boldsymbol{Q}$, Normalized non-cued responses for all subjects. $\boldsymbol{R}$, Accuracy and $(\boldsymbol{S})$ normalized accuracy across extinction. $\boldsymbol{T}$, Cued responses on day 5 of extinction, probe trial, and reinstatement trial.

phases (see Fig. 6A): magazine training, operant acquisition (Phase 1), and visuospatial discrimination (Phase 2). During operant acquisition, we illuminated all five nose-poke apertures, and a response into any aperture resulted in food reward. Mice advanced to visuospatial discrim- ination testing after reaching criteria ( $>15$ trials, 2 consecutive days). During visuospatial discrimination, we randomly illuminated one aperture during each trial, and we rewarded mice for nose-poking into the illuminated (cued) aperture. Mice reached criteria if they completed $>15$ 
trials with $>50 \%$ accuracy for 2 consecutive days. To quantify Phase 1 perseveration (see Fig. $6 D$ ), we rank-ordered aperture preference on the final $2 \mathrm{~d}$ of operant acquisition on a mouse-by-mouse basis. To quantify Phase 2 perseveration (see Fig. 6E), we carried over Phase 1 aperture preference and summed errors made for each aperture. We defined errors as nose-pokes into an aperture when it was not cued during a visuospatial discrimination trial.

Acute coronal slice preparation. We anesthetized mice with pentobarbital $(60 \mathrm{mg} / \mathrm{kg})$ and, after confirming the disappearance of corneal reflexes, transcardially perfused them with ice-cold dissection buffer (in mм: $87 \mathrm{NaCl}, 2.5 \mathrm{KCl}, 1.25 \mathrm{NaH}_{2} \mathrm{PO}_{4}, 26 \mathrm{NaHCO}_{3}, 75$ sucrose, 10 dextrose, 1.3 ascorbic acid, $7 \mathrm{MgCl}_{2}$, and $0.5 \mathrm{CaCl}_{2}$ ) bubbled with $95 \% \mathrm{O}_{2}$ and $5 \% \mathrm{CO}_{2}$. We then rapidly dissected the anterior forebrain, which we sectioned into $300-\mu \mathrm{m}$-thick coronal slices using a VT1000S vibrating microtome (Leica). We allowed slices to recover for $20 \mathrm{~min}$ in a $35^{\circ} \mathrm{C}$ submersion chamber filled with oxygenated artificial CSF [ACSF; containing the following (in $\mathrm{mm}$ ): $124 \mathrm{NaCl}, 3 \mathrm{KCl}, 1.25 \mathrm{NaH}_{2} \mathrm{PO}_{4}, 26$ $\mathrm{NaHCO}_{3}, 1 \mathrm{MgCl}_{2}, 2 \mathrm{CaCl}_{2}$, and 20 dextrose], supplemented with 1.25 mM ascorbic acid. We then transferred the recovery chamber to room temperature where slices remained for a minimum of $40 \mathrm{~min}$ before recordings (Philpot et al., 2003).

Whole-cell current-clamp recordings. We placed coronal slices containing infralimbic cortex in a submersion chamber maintained at $30-32^{\circ} \mathrm{C}$ and perfused at $2 \mathrm{ml} / \mathrm{min}$ with oxygenated ACSF. We pulled patch pipettes from thick-walled borosilicate glass using a P2000 laser puller (Sutter Instruments), with open tip resistances between 2 and $5 \mathrm{M} \Omega$ when filled with internal solution containing the following (in $\mathrm{mm}$ ): 100 potassium gluconate, $20 \mathrm{KCl}, 10$ HEPES, 10 sodium phosphocreatine, 0.2 EGTA, 4 Mg-ATP, 0.3 Na-GTP, and 0.025 AlexaFluor 594, with pH adjusted to 7.25 and osmolarity adjusted to $\sim 295 \mathrm{mOsm}$ with sucrose. We visually targeted L5 pyramidal neurons for recording using an Axio Examiner microscope (Zeiss) equipped with infrared differential interference contrast and epifluorescence optics, and we confirmed their identity by visualizing the presence of dendritic spines and prominent apical dendrites (filled with AlexaFluor 594 dye) and by analyzing characteristic membrane properties. For successfully patched neurons, we achieved pipette seal resistances $>1 \mathrm{G} \Omega$, minimizing pipette capacitive transients before breakthrough. We performed current-clamp recordings in the whole-cell configuration using a MultiClamp 700B amplifier (Molecular Devices) with $10 \mathrm{kHz}$ digitization and a $2 \mathrm{kHz}$ low-pass Bessel filter. We monitored changes in series and input resistance throughout each experiment, and we discarded neurons if series resistance surpassed $25 \mathrm{M} \Omega$ or if series resistance or input resistance changed by $>25 \%$ during a recording. We used pCLAMP 10 software (Molecular Devices) for the acquisition and analysis of all data.

To examine membrane excitability, we injected neurons with an 800 $\mathrm{ms}$ depolarizing current pulse ranging up to $600 \mathrm{pA}$ in amplitude (10-30 pA increments, intertrial interval of 5 s) from a beginning holding potential of -65 to $-70 \mathrm{mV}$. We determined each neuron's maximum instantaneous firing frequency using the formula 1/ISI, where ISI corresponds to the first interspike interval from the action potential train with the maximum frequency. From these experiments we also established frequency-current $(F-I)$ curves by determining the action potential frequency evoked at each level of injected current. We calculated slope from the linear portion of the $F-I$ curve. We obtained rheobase measurements from separate experiments in which we injected neurons with a ramping current $(0.25 \mathrm{pA} / \mathrm{ms})$ up to $200 \mathrm{pA}$. We also used the ramp experiments to determine the voltage threshold for action potential generation, which we defined as the point for the first action potential where $\mathrm{d} V_{\mathrm{m}} / \mathrm{dt}$ reached 10 $\mathrm{V} / \mathrm{s}$. For each neuron we measured the amplitude of fast afterhyperpolarizing potentials (fAHP) following the second current-evoked action potentials generated during the $800 \mathrm{~ms}$ pulse that produced the maximum action potential frequency. Specifically, we subtracted the voltage at the peak of the fAHP from the voltage threshold potential $\left(\mathrm{dV}_{\mathrm{m}} / \mathrm{dt}=\right.$ $10 \mathrm{~V} / \mathrm{s}$ ) for each spike's initiation. We measured medium afterhyperpolarizing potentials (mAHPs) and slow afterhyperpolarizing potentials (sAHPs) after the end of the $800 \mathrm{~ms}$ pulse, taking the average values generated across the range of current pulses injected into each neuron. We measured mAHP as the peak amplitude of the AHP following the 800 ms pulse, and sAHP as the average potential during a $50 \mathrm{~ms}$ period beginning $280 \mathrm{~ms}$ after the end of the $800 \mathrm{~ms}$ pulse (Sah and Faber, 2002). We derived individual action potential statistics (i.e., amplitude, halfwidth, maximum rate of rise) from the first action potential generated within $15 \mathrm{~ms}$ of the onset of the $800 \mathrm{~ms}$ current pulse. We provide measurements of resting membrane potential $\left(V_{\mathrm{m}}\right)$ without adjustment for junction potential.

Conditional deletion of Ube3a. We diluted tamoxifen (Sigma-Aldrich) in corn oil at a concentration of $20 \mathrm{mg} / \mathrm{ml}$. To induce deletion of Ube $3 a$, we administered (i.p.) corn oil vehicle (VEH) or tamoxifen (TAM; 0.1 mg per gram body weight) for 7 consecutive days. We waited exactly $14 \mathrm{~d}$ after tamoxifen dosing to test behavioral retention (see Fig. $3 A$ ), and 14 or more days after tamoxifen dosing for electrophysiological experiments (see Fig. 4A). We confirmed successful deletion of maternal Ube3a with Western blotting and immunofluorescence in the same animals used for behavioral experiments (see Fig. 3).

Western blotting. After behavioral experiments, we killed mice and rapidly harvested their brains, which we flash-froze, and later homogenized in RIPA buffer [50 mm Tris- $\mathrm{HCl}$ pH 7.4, $150 \mathrm{~mm} \mathrm{NaCl}, 1 \%$ Triton $\mathrm{X}-100,0.1 \%$ SDS, $0.5 \%$ sodium desoxycholate, 5 mм EDTA pH 8.0, Roche Complete Protease Inhibitor Cocktail (11697498001, SigmaAldrich)] to extract proteins. We resolved protein lysates by SDS-PAGE (20 $\mu \mathrm{g}$ of total protein per sample, $7.5 \%$ polyacrylamide gels), and transferred them to $0.2 \mu \mathrm{m}$ nitrocellulose membranes (1620112, Bio-Rad). We blocked membranes with 5\% nonfat dry milk dissolved in $0.01 \mathrm{~m}$ PBS containing $0.1 \%$ Tween 20 (PBST) for $1 \mathrm{~h}$ at room temperature. We incubated membranes with primary antibodies against UBE3A (1:1000; E6AP-clone 330, E8655, Sigma-Aldrich) for $1 \mathrm{~h}$ and $\beta$-tubulin (1:5000; 2146S, Cell Signaling Technology) for $2 \mathrm{~h}$ at room temperature. Following repeated washes with PBST, we incubated membranes with secondary antibodies for $1 \mathrm{~h}$ at room temperature: AlexaFluor 680-conjugated goat anti-mouse $\operatorname{IgG}_{1}$ (1:5000; A31562, Invitrogen) or IRDye 800CWconjugated donkey anti-rabbit (1:5000; 926-32213, LI-COR Biosciences). We visualized immunoreactive bands using the Odyssey Infrared Imaging System (LI-COR Biosciences), from which we determined ratios of UBE3A to total $\beta$-tubulin-immunoreactive band intensity. We normalized UBE3A-tubulin ratios for each sample to the average UBE3A-tubulin ratio obtained from two WT/VEH samples run on the same gel (see Fig. 3C).

Immunofluorescence. After behavioral experiments, we anesthetized mice with sodium pentobarbital $(60 \mathrm{mg} / \mathrm{kg})$ before transcardial perfusion with $0.01 \mathrm{M}$ PBS, followed immediately by phosphate-buffered $4 \%$ paraformaldehyde (PFA), $\mathrm{pH}$ 7.4. We postfixed brains overnight in PFA at $4^{\circ} \mathrm{C}$ before cryoprotecting them via incubation in $30 \%$ sucrose in PBS and sectioning them to a thickness of $40 \mu \mathrm{m}$ on a freezing microtome (ThermoFisher Scientific). For immunofluorescent staining (see Fig. $3 D$ ), we first permeabilized sections with $0.2 \%$ Triton X-100 in $0.01 \mathrm{~m}$ PBST for $30 \mathrm{~min}$, and then blocked with 5\% normal goat serum in PBST for $1 \mathrm{~h}$ at room temperature. We incubated blocked sections with mouse $\operatorname{IgG}_{2 \mathrm{~A}}$ anti-UBE3A (1:1000; clone 3E5, SAB1404508, Sigma-Aldrich) and mouse $\operatorname{IgG}_{1}$ anti-NeuN (1:500; MAB377, Millipore) overnight at $4^{\circ} \mathrm{C}$. The next day, we washed sections several times with PBST, and incubated them with AlexaFluor 488-conjugated anti-mouse $\operatorname{IgG}_{2 \mathrm{~A}}$ (1:500; A21131, Invitrogen), AlexaFluor 568-conjugated anti-mouse $\operatorname{IgG}_{1}$ (1:500; A21124, Invitrogen), and 4',6-diamidino-2-phenylindole (DAPI; $7 \mathrm{mg} / \mathrm{ml}$, D1306, Invitrogen) during the secondary antibody incubation for nuclear counterstaining. We stained drop-fixed slices from electrophysiological experiments (see Fig. 4B) using the same UBE3A staining protocol, with the exception that we extended the primary antibody incubation to $72 \mathrm{~h}$. We imaged sections via laser-scanning confocal microscopy (Zeiss LSM 710 and 780).

Experimental design and statistical analysis. We used GraphPad Prism 7 and SPSS to perform statistical analyses. For Figure 1, we used Student's $t$ tests to compare pre-extinction performance between groups (Fig. $1 C-$ $E, G$, right, $H$, right), and two-way repeated-measures (RM) ANOVAs to compare behavioral performance across groups over time (Fig. $1 I, J, L-$ $P, R-T$ ). For Figure 2, we used a two-way RM ANOVA (with current as the repeated measure) to compare $F-I$ curves between groups (Fig. $2 B$ ), 

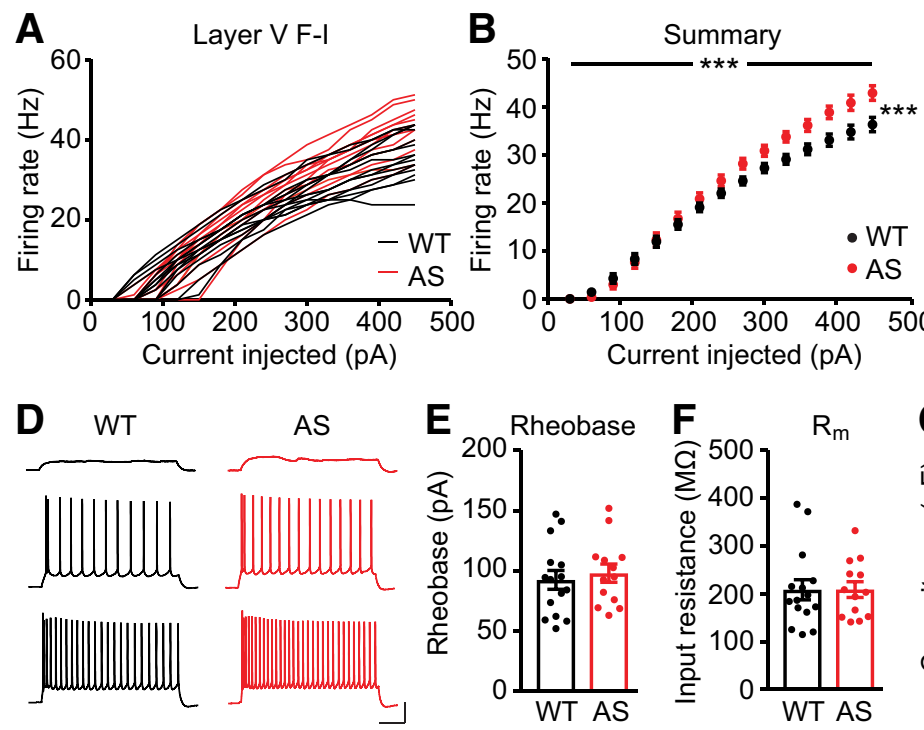

Figure 2. Increased excitability in infralimbic cortex in AS model mice. Current versus firing frequency $(F-I)$ relationships in $(\boldsymbol{A})$ individual layer $V$ pyramidal neurons and $(\boldsymbol{B})$ summarized across all neurons (asterisks indicate genotype $\times$ current interaction and post hoc test). C, Slope of $F-I$ curves is increased in AS neurons. $D$, Example current-clamp recordings illustrating increased excitability in AS. Top, 90 pA; middle, 180 pA; bottom, 360 pA. Scale bar: $25 \mathrm{mV}, 150 \mathrm{~ms}$. $\boldsymbol{E}$, Rheobase, $(\boldsymbol{F})$ input resistance, and (G) capacitance group comparisons. WT: $n=15$ cells ( 8 mice); AS: $n=13$ cells (7 mice).

Table 1. Electrophysiological properties of infralimbic neurons in AS model mice

\begin{tabular}{lrrr}
\hline Property & \multicolumn{1}{c}{ WT } & \multicolumn{1}{c}{ AS } & $p$ value \\
\hline$V_{\mathrm{m}}, \mathrm{mV}$ & $-74.5 \pm 1.3$ & $-73.4 \pm 0.7$ & 0.492 \\
$R_{\mathrm{s}}, \mathrm{M} \Omega$ & $15.8 \pm 0.6$ & $16.1 \pm 0.9$ & 0.761 \\
Spike threshold, $\mathrm{mV}$ & $-41.8 \pm 0.8$ & $-40.6 \pm 0.6$ & 0.235 \\
$I_{\mathrm{h}}, \mathrm{mV}$ & $43.8 \pm 7.8$ & $47.0 \pm 5.8$ & 0.746 \\
$\mathrm{sAHP}, \mathrm{mV}$ & $-1.4 \pm 0.2$ & $-1.2 \pm 0.1$ & 0.426 \\
$\mathrm{mAHP}, \mathrm{m}$ & $-3.4 \pm 0.2$ & $-3.2 \pm 0.2$ & 0.539 \\
$\mathrm{fAHP}, \mathrm{mV}$ & $-4.1 \pm 0.4$ & $-3.4 \pm 0.6$ & 0.358 \\
Max instantaneous firing frequency, $\mathrm{Hz}$ & $150.4 \pm 6.4$ & $160.2 \pm 7.4$ & 0.324 \\
AP amplitude, $\mathrm{mV}$ & $91.8 \pm 1.1$ & $91.9 \pm 1.1$ & 0.933 \\
AP half-width, ms & $0.64 \pm 0.01$ & $0.67 \pm 0.03$ & 0.477 \\
AP max rise, $\mathrm{mV} / \mathrm{ms}$ & $481.2 \pm 12.2$ & $490.1 \pm 16.0$ & 0.659 \\
\hline
\end{tabular}

and Student's $t$ tests for other group comparisons (Fig. 2C,E-G). For Table 1, we used Student's $t$ tests for all measures noted. For Figure 3, we used a two-way ANOVA to assess deletion of UBE3A protein, with genotype and treatment as factors (Fig. $3 C$ ). To assess performance between acquisition and retention (Fig. $3 E, F$ ) and to assess extinction (Fig. $3 G, H)$, we used three-way ANOVAs with time as a repeated measure, and genotype and treatment as factors. For Figure 4 and Table 2, we used the same statistical tests as in Figure 2 and Table 1. For Figure 5, we used a two-way RM ANOVA (with time as the repeated measure) to assess acquisition (see Fig. 5C) and extinction (see Fig. 5D) between groups. For Figure 6, we used Student's $t$ tests to assess performance on operant acquisition and visuospatial discrimination (see Fig. 6B,C). We used two-way ANOVAs to assess perseveration (see Fig. $6 D, E$ ), with genotype and aperture as factors. For all ANOVAs, we used post hoc Bonferroni tests to make within-group comparisons while correcting for multiple comparisons. In Figure 1, $L$ and $M$, minute-by-minute data on day 1 of extinction (E1) were not saved for one WT animal; this animal was excluded from minute-by-minute analyses only (full session data were preserved). For electrophysiology data, we defined and removed two outliers based on input resistance using a Grubb's outlier test with $\alpha=$ 0.01 : one AS cell $\left(R_{\mathrm{m}}=590 \mathrm{M} \Omega\right)$ and one WT/TAM cell $\left(R_{\mathrm{m}}=612 \mathrm{M} \Omega\right)$. For all figures: ${ }^{\star} p<0.05,{ }^{\star *} p<0.01,{ }^{* *} p<0.001$, and error bars represent SEM.
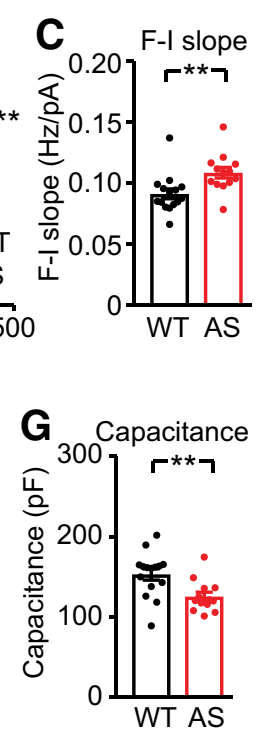

\section{Results}

Operant extinction is exaggerated in AS model mice

We tested the performance of AS model mice $\left(U b e 3 a^{m-p^{+}}\right)$and wild-type (Ube3a $a^{m+/ p+}$, WT) littermates on five stages of an operant behavioral task: (1) magazine training, (2) acquisition, (3) extinction, (4) probe, and (5) reinstatement (Fig. 1A,B). Mice were food-restricted and thus motivated to receive food pellet rewards. During magazine training, mice received a reward for every nose-poke into the food magazine. WT and AS mice performed equally during magazine training (Fig. 1C; Student's $t$ test: $t_{(22)}=0.3807, p=0.701$ ), suggesting no difference in motivation or reward salience between groups. During operant acquisition, mice were rewarded for nose-poking into the illuminated aperture (cued response). We quantified operant acquisition as the number of days to reach predefined criteria $(>15$ trials, $>75 \%$ accuracy, 5 consecutive days). Operant acquisition was not statistically different between AS and WT mice, though AS mice trended toward delayed acquisition (Fig. $1 D ; t_{(22)}=$ $1.888, p=0.0723$ ). Trained mice typically performed at a level exceeding 90\% accuracy, and trained AS mice were slightly more accurate than WT littermates (Fig. $1 E ; t_{(22)}=3.026, p=0.0062$ ). High accuracy after acquisition training reflected a learned increase in cued responses across training with little change in noncued responses (Fig. $1 F$ ). When mice reached criteria for successful operant acquisition, the number of cued responses during these five sessions "at criteria" was not different between genotypes (Fig. $1 G$, right: $t_{(22)}=1.845, p=0.0785$ ). However, the number of non-cued responses at criteria was decreased in AS mice (Fig. $1 H$, right; $t_{(22)}=3.696, p=0.0013$ ). Thus, although non-cued responses represented a small fraction of total responses, the slight increase in accuracy in AS mice (Fig. 1E) reflects a decrease in non-cued responses, and not a change in cued responses. Overall, we conclude that operant acquisition is largely normal in AS mice, though we do report statistically nonsignificant trends toward a delay in the number of days to reach acquisition criteria and a decrease in the number of cued responses at criteria.

Following acquisition, mice underwent $5 \mathrm{~d}$ of extinction testing in the absence of food reward. AS mice showed exaggerated extinction of cued responses (Fig. 1I; two-way RM ANOVA: main effect of genotype: $F_{(1,22)}=13.90, p=0.0012$, genotype $\times$ time interaction: $\left.F_{(4,88)}=7.008, p<0.0001\right)$. To account for the trend toward a slightly lower cued response rate during acquisition in AS mice (Fig. 1G,I, ACQ), we normalized the number of cued responses during extinction to the number of cued responses during acquisition, within animals. Exaggerated extinction in AS mice persisted with normalization (Fig. $1 \mathrm{~J}, \mathrm{~K}$; main effect of genotype: $F_{(1,22)}=7.351, p=0.0128$; genotype $\times$ time interaction: $F_{(4,88)}=$ $4.835, p=0.0014)$, confirming that this phenotype is not driven by a difference in acquisition. Exaggerated extinction was rapid, and driven primarily by a genotype difference on the first day of extinction (post hoc tests for Fig. $1 I, J: t_{(110)}=6.331$ and $t_{(110)}=$ $5.016, p<0.0001$ for E1). During E1, phenotypes emerged in AS 
mice in the first 5 min of the session (Fig. $1 L$; main effect of genotype: $F_{(1,21)}=$ $8.590, p=0.0080$; genotype $\times$ time interaction: $F_{(2,42)}=1.538, p=0.227$; post hoc tests: $0-5$ min: $t_{(63)}=3.245, p=0.0056$; 5-10 min: $t_{(63)}=1.738, p=0.2615$; $10-15$ min: $\left.t_{(63)}=2.635, p=0.0317\right)$.

We next assessed whether the genotype difference in cued responding on day E1 could reflect impaired consolidation, rather than extinction, in AS mice. The number of cued responses during the first minute of extinction was not different between groups, suggesting AS mice had normal consolidation. Rather, differences in cued responses in AS mice emerged after the first minute (Fig. 1M; main effect of genotype: $F_{(1,105)}=29.91, p<0.0001$; genotype $\times$ time interaction: $F_{(4,105)}=1.229$, $p=0.303$; post hoc tests: $\min 1: t_{(105)}=$ $1.21, p>0.9999 ; \min 2: t_{(105)}=3.337, p=$ 0.0059; $\min 3: t_{(105)}=1.568, p=0.5998$; $\min 4: t_{(105)}=3.791, p=0.0013 ; \min 5$ : $\left.t_{(105)}=2.324, p=0.1103\right)$. To further test whether consolidation of operant learning was different between groups, we also quantified the number of cued responses during the first $5 \mathrm{~min}$ of the final day of acquisition (ACQ5). During this time period, there was no difference in cued responses between WT and AS mice (Fig. $1 N$; no main effect of genotype: $F_{(1,110)}=$ $1.061, p=0.3051$; genotype $\times$ time interaction: $\left.F_{(4,110)}=0.6866, p=0.6027\right)$. Therefore, the decrease in cued responses in AS mice during the first 5 min of session E1 reflects a genotype difference in extinction, and not in consolidation.

Nose-pokes into the non-illuminated aperture (non-cued responses) were used to assess whether mice would adjust their reward-seeking strategy coincident with extinction. For example, an increase in non-cued responses during extinction might reflect cognitive flexibility. AS mice had fewer non-cued responses during extinction (Fig. 1O; main effect of genotype: $\left.F_{(1,22)}=10.63, p=0.0036\right)$. However, interpretation of this phenotype is challeng-

ing because AS mice also had fewer non-cued responses during acquisition (Fig. 1 H, O, ACQ). To correct for the genotype difference in non-cued responses during acquisition, we normalized the number of responses during extinction to the number of responses during acquisition. We found that normalization abolishes the genotypic difference in non-cued responses (Fig. $1 P, Q$; no main effect of genotype: $\left.F_{(1,22)}=1.399, p=0.2495\right)$. We also confirmed that accuracy did not change in a genotypespecific manner during extinction (Fig. $1 R$; genotype $\times$ time interaction: $F_{(4,88)}=0.0017, p=0.8738$; Fig. $1 S$; genotype $\times$ time interaction: $\left.F_{(4,88)}=0.3437, p=0.8477\right)$. The increased accuracy in AS mice seen during acquisition (Fig. 1E) was also seen across extinction (Fig. $1 R$; main effect of genotype: $F_{(1,22)}=$ 5.398, $p=0.0298)$. Therefore, AS model mice did not show
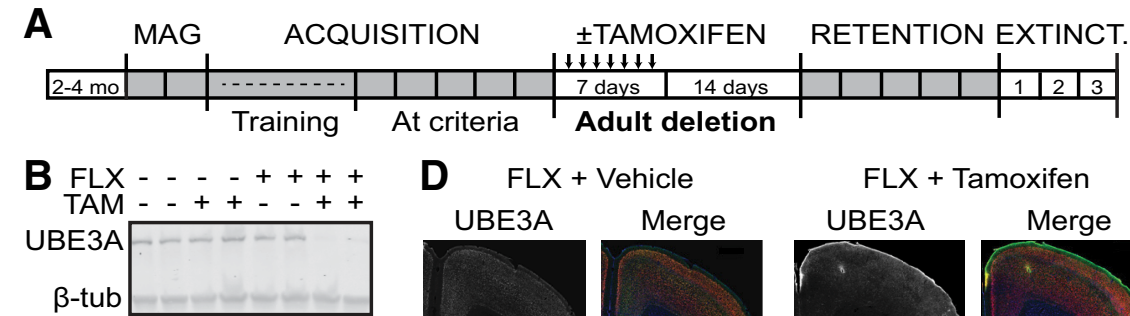

D $\mathrm{FLX}+$ Vehicle

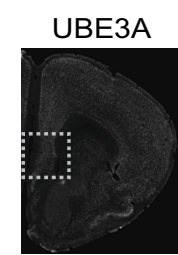

Merge

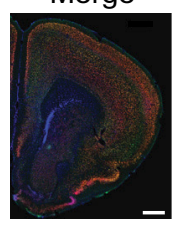

UBE3A

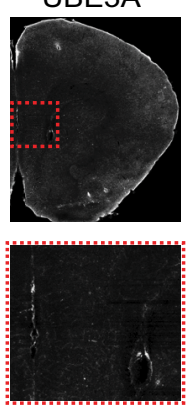

Merge
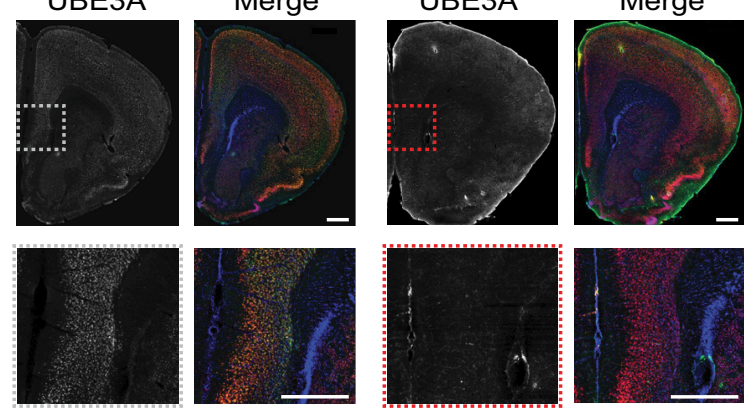

F

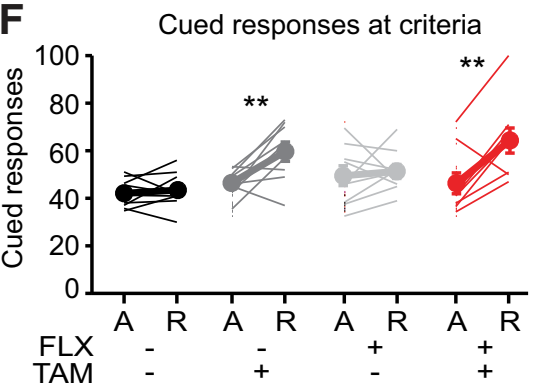

G Cued responses (normalized)
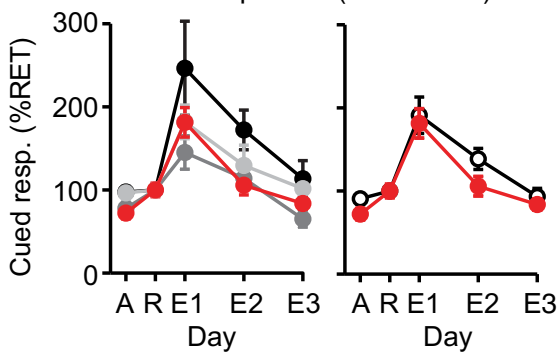

H Non-cued responses (normalized)

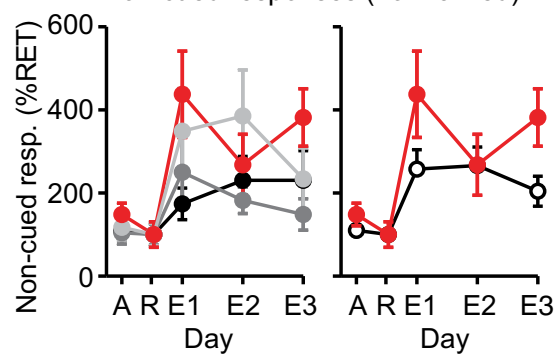

- WT/VEH $\odot$ FLX/VEH OUBE3A present - WT/TAM • FLX/TAM - UBE3A absent

Figure 3. Extinction is unaltered by adult deletion of Ube3a. $\boldsymbol{A}$, Experimental timeline, including TAM or VEH administration between acquisition and retention phases. $\boldsymbol{B}$, Example Western blots and $(\boldsymbol{C})$ quantified Western data showing successful deletion coronal slices including IL. Top, wide view; bottom, zoomed on IL. Scale bars, $500 \mu \mathrm{m}$. Merged images: UBE3A, green; DAPI, blue; NeuN, red. $\boldsymbol{E}$, Response accuracy at criteria during acquisition $(A)$ and retention (R) phases ( $n=9$ for all groups). $\boldsymbol{F}$, Cued responses at criteria during acquisition and retention phases. $\mathbf{G}$, Cued and $(\boldsymbol{H})$ non-cued responses over $3 \mathrm{~d}$ of extinction. Left, All data. Right, Condensed data (Ube3a present: $n=27$; Ube3a absent: $n=9$ ).

a change in response strategy following removal of food reward.

To test whether extinction memories were long-lasting, we conducted a probe trial with no reward 4 weeks after extinction. In both WT and AS mice, extinction learning was retained after this long delay: cued responses were similar between the last day of extinction (E5) and the probe trial (Fig. 1T; no significant main effect of time, genotype, or time $\times$ genotype interaction). After the probe trial, we reinstated food reward for one session. Reinstatement increased the number of cued responses (Fig. 1T; main effect of time: $F_{(1,22)}=27.8, p<$ 0.0001 ), but did not do so in a genotype-specific way (no time $\times$ genotype interaction: $\left.F_{(1,22)}=1.325, p=0.2620\right)$. 
Overall, operant extinction was robustly and rapidly exaggerated in AS model mice.

\section{Infralimbic neurons are hyperexcitable in AS model mice}

Behavioral extinction increases the firing rates of IL prefrontal neurons in vivo (Milad and Quirk, 2002) and the excitability of IL neurons ex vivo (Santini et al., 2008). Because AS mice showed exaggerated extinction (Fig. 1), we hypothesized that IL neurons would be hyperexcitable in AS, potentially priming circuits for exaggerated extinction. We measured IL excitability in ex vivo slices from behaviorally naive animals by injecting steps of depolarizing current into layer $\mathrm{V}$ pyramidal neurons and quantifying their firing rates ( $F-I$ curves). IL neurons from AS mice showed increased excitability relative to WT littermates (Fig. $2 A-D ; B$ : genotype $\times$ current interaction: $F_{(14,390)}=2.905, p=0.0003$; steady-state post hoc: $p=0.0007$; $\left.C: t_{(26)}=2.907, p=0.0074\right)$. Layer V IL neurons from AS mice did not show a shifted rheobase (Fig. $2 E ; t_{(26)}=0.5129, p=0.6142$ ) or input resistance (Fig. 2F; $\left.t_{(26)}=0.0171, p=0.9865\right)$, but did show decreased capacitance (Fig. 2G; $t_{(26)}=2.981, p=0.0062$ ). Decreased capacitance in adult AS mice has been previously reported in primary visual cortex (Yashiro et al., 2009; Wallace et al., 2012), and suggests that AS neurons may be smaller than WT neurons. Other electrophysiological properties of layer V IL neurons were normal in AS mice (Table 1).

\section{Inducible deletion of Ube3a in adulthood does not affect extinction}

Recent work used inducible genetic approaches to reinstate Ube $3 a$ at various developmental time points (Silva-Santos et al., 2015). Adult reinstatement of Ube3a did not correct any behavioral phenotype tested in AS mice (rotarod, nest building, open field, forced swim, or marble burying). However, adult Ube3a reinstatement was sufficient to correct deficient hippocampal longterm potentiation (LTP). Overall, this work suggested that while there is a critical period for development and correction of behavioral phenotypes in AS, this critical period may not extend to certain cellular phenotypes. Because extinction is directly linked to cellular excitability (Santini et al., 2008; Criado-Marrero et al., 2014; Cruz et al., 2014), we reasoned that extinction may be exempt from this early critical period. Thus we hypothesized that deleting Ube3a in adult mice would be sufficient to induce exaggerated behavioral extinction. We bred experimental animals with expression of tamoxifen-inducible Cre (CAG-Cre ${ }^{\mathrm{ERT}}$; Hayashi and McMahon, 2002) that were WT at the Ube3a locus [Ube $3 a^{m+/ p+}::$ CAG-Cre ${ }^{\text {ERT }}$ (WT)] or carried a floxed maternal Ube $3 a$ allele [Ube $3 a^{F L X / p+}:: C A G-C r e^{\mathrm{ERT}}$ (FLX); Judson et al., 2016]. We administered tamoxifen or vehicle following operant acquisition to test how adult deletion of Ube3a modulates operant extinction, independent of acquisition (Fig. 3A). Tamoxifen dosing successfully reduced UBE3A protein in FLX mice to $\sim 10 \%$ of WT levels (Fig. $3 B, C$; genotype $\times$ treatment interaction: $\left.F_{(1,27)}=46.55, p<0.0001\right)$. Immunofluorescence confirmed that tamoxifen administration deleted Ube3a in IL PFC (Fig. 3D).

Using a 3 week drug administration protocol (Fig. $3 A$ ) provided two challenges in measuring extinction. First, immediate extinction testing after drug treatment would be confounded by the long delay after acquisition. Second, immediate extinction testing would not take into account possible acute side effects of tamoxifen or of animal handling. To address these concerns, we first assessed retention following drug treatment. During the re- tention phase, the performance of every mouse remained above acquisition criteria, with response accuracy remaining $>90 \%$ (Fig. 3E). Thus, mice retained learning after the 3 week delay. Tamoxifen itself increased the number of cued responses, but did so independent of Ube3a genotype (Fig. 3F; three-way ANOVA: time $\times$ treatment interaction: $\left.F_{(1,32)}=12.4940, p=0.0013\right)$. Post hoc tests revealed that both WT/TAM $(p=0.0091)$ and FLX/ TAM $(p=0.0003)$ groups had more cued responses during retention than acquisition. Aside from its role in inducing Cre-mediated recombination, tamoxifen is a modulator of estrogen receptors (Lonard and Smith, 2002) and can have side effects in mice including gastric toxicity and hepatotoxicity (Huh et al., 2012; Gao et al., 2016). The increased response rate following tamoxifen treatment suggests that these or other side effects may affect motivation, reward salience, or motor activity. Therefore, we normalized all extinction data to the number of responses during retention, rather than to acquisition (Fig. 3G,H).

FLX/TAM mice exhibited cued responses during extinction learning in a pattern similar to Ube3a-expressing groups (WT/ VEH, WT/TAM, and FLX/VEH); thus, adult deletion of Ube3a was not sufficient to drive exaggerated extinction (Fig. $3 G$, left; three-way ANOVA, genotype $\times$ treatment interaction: $F_{(1,31)}=$ $2.1955, p=0.1485)$. To simplify data presentation, we combined genotype and treatment to visualize only two groups: Ube3aexpressing and nonexpressing (Fig. 3G, right). Adult Ube3a deletion also had no effect on non-cued responses (Fig. $3 H$; genotype $X$ treatment interaction: $\left.F_{(1,31)}=0.2200, p=0.6423\right)$. Overall, we confirmed that adult Ube3a deletion did not affect operant extinction, which suggests that there is likely a critical period for development of this phenotype.

\section{Inducible deletion of Ube3a in adulthood increases IL excitability}

Adult Ube3a deletion may fail to induce enhanced extinction if it does not concomitantly increase the excitability of neurons in IL PFC. We addressed this possibility by deleting Ube3a in adulthood and measuring the excitability of layer $\mathrm{V}$ excitatory pyramidal neurons in IL (Fig. 4A,B). Neurons from FLX/TAM mice showed increased excitability compared with WT/TAM littermate controls (Fig. $4 C$; $D$ : genotype $\times$ current interaction: $F_{(12,456)}=$ 3.968, $p<0.0001$; steady-state post hoc: $p=0.0509)$. In this group, the increase in excitability was not driven by an increase in $F-I$ slope (Fig. $4 E ; t_{(38)}=1.296, p=0.2028$ ), but rather by a leftward shift in $F-I$ curves due to a decreased rheobase (Fig. $\left.4 F, G: t_{(38)}=2.66, p=0.0114\right)$. The decreased rheobase in the FLX/TAM group may be driven in part by an increase in input resistance (Fig. $4 \mathrm{H} ; t_{(38)}=2.245, p=0.0307$ ). Notably, adult deletion of Ube3a was not sufficient to change the capacitance of layer V neurons (Fig. $4 I ; t_{(38)}=1.049, p=0.3010$ ), indicating that deficits in the somatodendritic growth of neurons in AS model mice might arise during early postnatal development. Other properties of layer 5 IL neurons in FLX/TAM mice were largely normal (Table 2). Overall, adult deletion of Ube3a was sufficient to increase the excitability of IL neurons, but not sufficient to drive exaggerated behavioral extinction.

\section{Cued fear extinction is normal in AS model mice}

Encoding of operant extinction and associative extinction use similar prefrontal mechanisms (Peters et al., 2008, 2009; LaLumiere et al., 2010; Marchant et al., 2010; Kaplan et al., 2011; Millan et al., 2011). Thus we hypothesized that associative (cued) fear extinction would also be enhanced in AS model mice. We trained 
mice to associate a conditioned stimulus (tone) with an unconditioned stimulus (footshock). Training consisted of toneshock pairings, and we tested acquisition and extinction of cued fear by measuring freezing in the presence of the tone alone (Fig. 5A,B). AS mice showed normal acquisition of cued fear (Fig. $5 C$; two-way ANOVA; main effect of cue: $F_{(1,30)}=$ 42.25, $p<0.0001$; no effect of genotype: $F_{(1,30)}=0.8107, p=0.3751$; no cue $\times$ genotype interaction: $F_{(1,30)}=0.0353, p=$ 0.8523). AS mice also showed normal cued fear extinction (Fig. 5D; main effect of time: $F_{(3,90)}=3.335, p=0.0229$; no effect of genotype: $F_{(1,30)}=0.0121, p=$ 0.9133 ; no time $\times$ genotype interaction: $\left.F_{(3,90)}=0.2955, p=0.8286\right)$. Thus, enhanced extinction did not generalize from operant to associative behaviors in AS model mice.

\section{Visuospatial discrimination is largely normal in AS model mice}

To test whether broad dysregulation of prefrontally encoded behavior is a feature of AS, we assessed performance of AS model mice on an operant visuospatial discrimination task that measures cognitive flexibility and is linked to prefrontal function (Krueger et al., 2011). Mouse models of Fragile $\mathrm{X}$ syndrome display both enhanced extinction and impaired visuospatial discrimination (Krueger et al., 2011; Sidorov et al., 2014). Fragile X and Angelman syndromes have a substantial degree of phenotypic overlap, including cognitive impairment, anxiety, neocortical hyperexcitability, and epilepsy (Schneider et al., 2009; Wallace et al., 2012; Thibert et al., 2013; Cea-Del Rio and Huntsman, 2014). Thus we hypothesized that AS mice would show similar impairments in visuospatial discrimination, including increased perseverative behavior while performing this assay. Before visuospatial discrimination testing, we first trained mice to reach acquisition criteria $(>15$ trials, 2 consecutive days; Fig. 6A). Operant acquisition was slightly delayed in AS mice (Fig. $6 B ; t_{(21)}=2.105, p=0.0475$ ), reminiscent of the trend toward delayed acquisition exhibited by AS mice during operant extinction (Fig. 1D). During visuospatial discrimination testing, one aperture was illuminated on each trial. Only responses into the illuminated ("correct") aperture resulted in reward. AS mice reached criteria for visuospatial discrimination ( $>15$ trials, $>50 \%$ accuracy, 2 consecutive days) at the same rate as WT mice (Fig. $6 C ; t_{(21)}=1.568$, $p=0.1318$ ).

We next tested perseverative behavior in AS mice. We rankordered aperture preference during operant acquisition on a mouse-by-mouse basis and found that AS model mice perseverated to a greater degree than WT mice (Fig. $6 D$; aperture $\times$ genotype interaction: $\left.F_{(4,80)}=3.952, p=0.0056\right)$. Post hoc tests revealed a significant difference in the rate of responses to the most preferred aperture $\left(t_{(100)}=3.939, p=0.0008\right)$. In addition, perseverative preferences developed during operant acquisition
Table 2. Electrophysiological properties of infralimbic neurons following adult Ube3a deletion

\begin{tabular}{lrcl}
\hline Property & \multicolumn{1}{c}{ WT } & Adult Ube3a deletion & $p$ value \\
\hline$V_{\mathrm{m}}, \mathrm{mV}$ & $-71.4 \pm 0.5$ & $-71.0 \pm 1.0$ & 0.299 \\
$R_{\mathrm{s}}, \mathrm{M} \Omega$ & $16.7 \pm 0.7$ & $17.3 \pm 1.0$ & 0.555 \\
Spike threshold, $\mathrm{mV}$ & $43.0 \pm 0.6$ & $43.2 \pm 1.1$ & 0.834 \\
$I_{\mathrm{h}}, \mathrm{mV}$ & $11.5 \pm 5.2$ & $15.1 \pm 7.9$ & 0.389 \\
$\mathrm{SAHP}, \mathrm{mV}$ & $-0.9 \pm 0.1$ & $-0.8 \pm 0.2$ & 0.886 \\
$\mathrm{mAHP}, \mathrm{mV}$ & $-3.2 \pm 0.1$ & $-2.7 \pm 0.3$ & 0.094 \\
$\mathrm{fAHP}, \mathrm{mV}$ & $-2.5 \pm 0.4$ & $-1.4 \pm 0.4$ & 0.102 \\
Max instantaneous firing frequency, $\mathrm{Hz}$ & $191.1 \pm 5.5$ & $200.7 \pm 8.1$ & 0.320 \\
AP amplitude, $\mathrm{mV}$ & $91.2 \pm 0.8$ & $88.8 \pm 2.0$ & 0.196 \\
AP half-width, ms & $0.62 \pm 0.01$ & $0.65 \pm 0.01$ & 0.0496 \\
AP max rise, $\mathrm{mV} / \mathrm{ms}$ & $477.5 \pm 9.5$ & $442.9 \pm 19.8$ & 0.082 \\
\hline
\end{tabular}

carried over to the visuospatial discrimination phase in the form of errors (nose-pokes to a non-illuminated aperture). During visuospatial discrimination, mice made more errors in preferred apertures, and this tendency was significantly increased in AS mice (Fig. $6 E$; aperture $\times$ genotype interaction: $F_{(4,80)}=4.642$, $p=0.0020$; post hoc test of most preferred aperture: $t_{(100)}=4.157$, $p=0.0003)$. Overall, AS mice learned the visuospatial discrimination task successfully, despite delayed operant acquisition and increased perseverative behavior. 

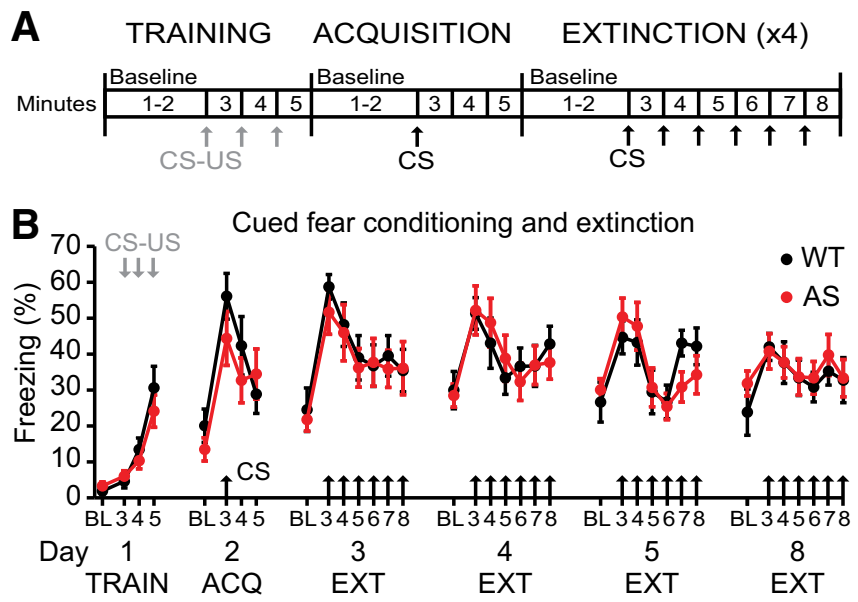

Figure 5. Cued fear extinction is normal in AS model mice. $\boldsymbol{A}$, Experimental timeline. $\boldsymbol{B}$, Raw data for all experimental days, plotted by minute. Baseline (BL) represents a 2 min average. C, Quantification of fear acquisition, measured on Day 2 of training. "3-5 min" represents average freezing across these time points. D, Quantification of fear extinction, measured across $4 \mathrm{~d}$. Freezing represents average freezing across minutes $3-8$ of sessions. WT: $n=16$; AS: $n=16$.

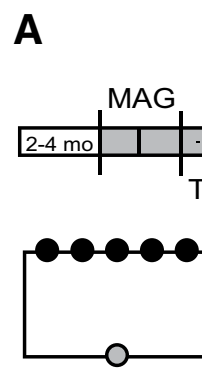

MAG
Operant acquisition PHASE 1

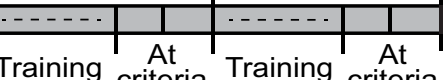

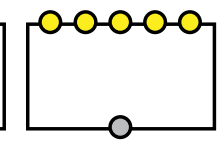

PHASE 1

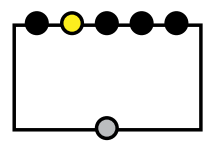

PHASE 2
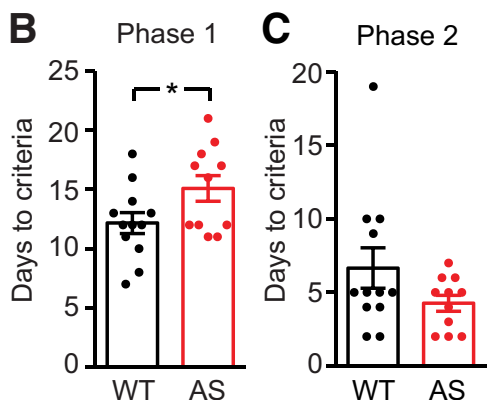

D

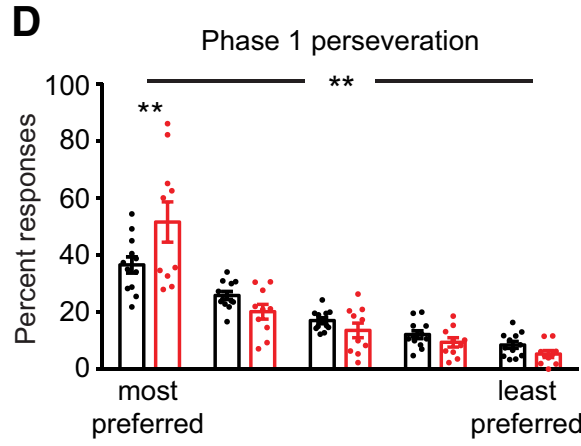

E

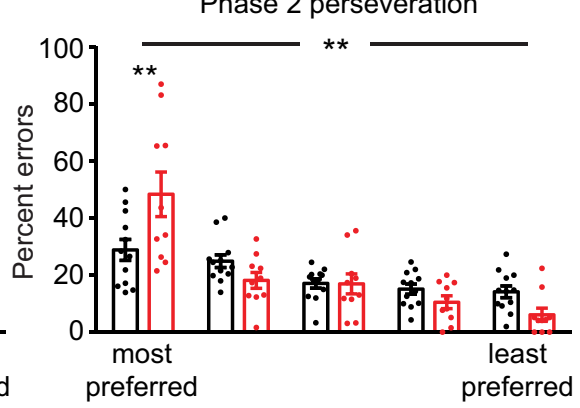

Phase 2 perseveration

Figure 6. Visuospatial discrimination is normal in AS model mice. A, Experimental timeline and schematics. All five nose-poke apertures were illuminated during operant acquisition, and one aperture was illuminated at a time during visuospatial discrimination. $\boldsymbol{B}$, Operant acquisition (Phase 1) was delayed in AS mice. C, Visuospatial discrimination (Phase 2) was normal in AS mice. $\boldsymbol{D}$, Perseverative behavior during Phase 1, and (E) perseverative behavior during Phase 2 were both increased in AS mice (asterisks indicate genotype $\times$ preference interaction and post hoc tests). WT: $n=12 ;$ AS: $n=11$.

\section{Discussion}

Cognitive impairment is a core feature of AS (Thibert et al., 2013). However, the repertoire of robust and reliable behavioral phenotypes in AS model mice has thus far been largely limited to noncognitive tasks. For example, AS mice reliably model seizures, motor impairments, and anxiety (Jiang et al., 1998; Miura et al., 2002; van Woerden et al., 2007; Heck et al., 2008; Huang et al., 2013; Bruinsma et al., 2015; Mandel-Brehm et al., 2015; SilvaSantos et al., 2015; Judson et al., 2016; Jamal et al., 2017). Hypersociability and hippocampally dependent learning impairments have also been reported with varying reliability (van Woerden et al.,
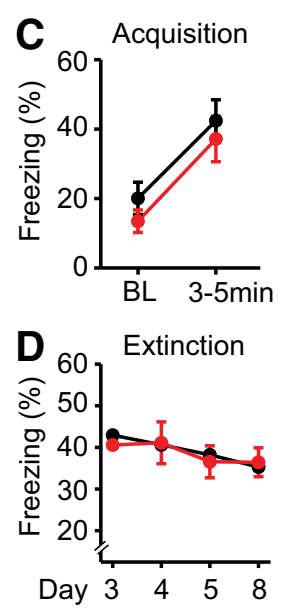

2007; Allensworth et al., 2011; Huang et al., 2013; Stoppel and Anderson, 2017). Here we showed that operant extinction, a behavior linked to prefrontal circuits, appears exaggerated in AS model mice. Consistent with enhanced operant extinction, we found that infralimbic pyramidal neurons are hyperexcitable in AS model mice. We propose that operant extinction provides a reliable method to model prefrontally encoded, cognitive-like behavior in AS.

Given that extinction is a form of active learning, and not merely "forgetting" (Bouton, 2004; de Carvalho Myskiw et al., 2015), it may seem counterintuitive that AS model mice show enhanced, and not impaired, extinction. This finding implies that AS mice learn faster than their wildtype littermates, and is not consistent with impaired performance in other behavioral domains. However, enhanced extinction is also seen in a mouse model of Fragile X syndrome, a related neurodevelopmental disorder (Dölen et al., 2007; Sidorov et al., 2014; Radwan et al., 2016). Thus, although the direction of the extinction phenotype may seem unexpected, it does appear consistent across disorders. In humans, the behavioral consequences of enhanced extinction are less obvious than the clear negative consequences associated with impaired extinction, especially in the context of post-traumatic stress disorder and addiction (Kaplan et al., 2011; VanElzakker et al., 2014). Given these considerations, we do not propose that enhanced extinction in AS model mice should be used to model enhanced extinction in individuals with AS. Rather, we propose that extinction provides a behavioral readout of cognitive dysfunction in a mouse model of AS. Such cognitive dysfunction may manifest behaviorally in other ways in the human population. For future studies of AS model mice, the advantage of measuring extinction lies not in its face validity, but in its robustness and in its potential link to prefrontal circuitry.

Behavioral extinction is typically defined as a decrease in cued responding following the removal of reward contingency. In our study, mice of both genotypes showed a potentially surprising increase in cued responding on the first day of extinction training, relative to acquisition (Fig. $1 I, J$ ). We attribute this result to a partial reinforcement extinction effect (Mackintosh, 1974; Chan and Harris, 2017), whereby resistance to extinction was driven by the use of variable reinforcement during acquisition training (see Materials and Methods). Such a short-lived increase in cued responses following the removal of reward contingency has been reported previously in an operant extinction study that used similar methods (Sidorov et al., 2014). However, the absolute increase in cued responses during day 1 of extinction 
training raises the possibility that no extinction has yet occurred, and that the "day E1" phenotype in AS mice reflects a different process. One possible explanation for the day E1 phenotype in AS mice is that it reflects a group difference in operant acquisition or consolidation. We found slightly delayed operant acquisition in AS mice. In one experiment this effect was statistically significant (Fig. $6 B ; p=0.0475$ ) and in another it was not (Fig. $1 D ; p=$ 0.072). This result is not entirely surprising considering other learning deficits in AS model mice; however, our predefined analysis criteria (including normalization) allowed us to measure extinction independent of slightly impaired acquisition. We confirmed that consolidation was normal in AS mice (Fig. $1 M, N$ ), and that a small but significant decrease in non-cued responding during acquisition (Fig. $1 H$ ) did not influence extinction (Fig. $1 O-S$ ). Thus it is unlikely that differences in operant acquisition or consolidation contribute to the day E1 behavioral phenotype in AS mice. Given these considerations, we conclude that the difference in cued responding on day 1 of extinction training likely reflects a genotype difference in extinction. However, we remain open to the possibility that this phenotype may reflect other processes for the following reasons: (1) although the number of cued responses was decreased in AS mice as early as the first $5 \mathrm{~min}$ of extinction testing (Fig. 1M), the rate of extinction was not statistically different during this time period, and (2) cued fear extinction was normal in AS mice (Fig. 5). One alternative explanation for the day E1 phenotype in AS mice could be a differential sensitivity to variable reinforcement. Future work should assess operant extinction in AS mice in other contexts, such as drugseeking or following training with fixed reinforcement.

We report increased excitability in IL neurons in AS (Fig. 2), which is consistent with the known link between IL excitability and behavioral extinction (Santini et al., 2008; Cruz et al., 2014). We hypothesize that increased excitability at baseline in AS mice may prime circuits for rapid behavioral extinction. Neocortical hyperexcitability is a common feature of many monogenic forms of autism, including Fragile X syndrome and Rett syndrome (Nelson and Valakh, 2015). In AS, hyperexcitable microcircuits have been described in primary visual cortex (Wallace et al., 2012), and our results represent the first report of hyperexcitability in prefrontal circuits. Broadly, our results suggest that hyperexcitability might be a feature of many neuron populations throughout cortex, and perhaps throughout the AS brain. However, we have not defined the precise mechanism by which such hyperexcitability occurs. UBE3A is an E3 ubiquitin ligase with many potential substrates (LaSalle et al., 2015; Sell and Margolis, 2015), including ion channels (Sun et al., 2015); therefore, it is possible that loss of UBE3A may regulate excitability through different mechanisms in different brain regions. Moreover, "hyperexcitability" is a catch-all term, potentially encompassing a wide range of synaptic, intrinsic, and circuit-level mechanisms (Nelson and Valakh, 2015). For example, hyperexcitability in V1 microcircuits and hyperexcitability at the level of seizures and EEG are not regulated by the same processes in AS (Judson et al., 2016). We showed that infralimbic neurons from both AS mice (Fig. 2) and adult Ube3a deletion mice (Fig. 4) displayed increased excitability; however, the expression of increased excitability was different between groups: AS neurons showed an increased $F-I$ slope and normal rheobase, whereas adult deletion induced a leftward shift in rheobase and no change in $F-I$ slope. This indicates that the timing of maternal Ube3a loss during development may influence the membrane excitability of neurons through distinct mechanisms.
Inducible deletion of Ube3a in adulthood was sufficient to increase the excitability of IL neurons but not sufficient to recapitulate exaggerated behavioral extinction (Figs. 3, 4). These results are consistent with the finding that adult reinstatement of Ube 3 a corrects hippocampal LTP but not behavior (Silva-Santos et al., 2015). Our results support the idea that there is an early critical period during which absence of Ube3a drives Angelmanlike behavior. While cellular phenotypes (such as excitability) may be amenable to manipulating Ube3a beyond this critical period, behavioral phenotypes are impervious to such manipulations. In this regard, AS may diverge from Fragile X: adult deletion of the Fragile X-causing protein (FMRP) is sufficient to recapitulate prefrontally encoded behavioral phenotypes (Siegel et al., 2017). In our study, the dissociation between IL excitability and extinction was predictable given the known critical period for how Ube $3 a$ expression modulates behavior, but was surprising given the established link between these processes. We hypothesize that the presence of Ube3a during development shapes circuits downstream of IL cortex such that animals become behaviorally untethered from acute changes in IL excitability. Alternatively, mechanistic differences in how increased excitability is expressed may account for behavioral differences between AS mice and mice where Ube3a was deleted in adulthood.

Extinction has been linked to prefrontal circuits across multiple contexts, including fear conditioning and operant procedures that use food and drug reward (Peters et al., 2008, 2009; LaLumiere et al., 2010; Marchant et al., 2010; Kaplan et al., 2011; Millan et al., 2011). Thus given enhanced operant extinction in AS model mice, we were surprised to find that fear extinction was normal (Fig. 5). Although IL circuits are involved in both processes, downstream targets of IL neurons are different between fear extinction and operant extinction: fear extinction modulates IL projections to the basolateral amygdala, whereas operant extinction modulates IL projections to the nucleus accumbens shell (Peters et al., 2008; Cho et al., 2013). We hypothesize that behavioral differences between fear and operant extinction in AS mice may emerge downstream of IL.

Beyond fear extinction, we tested one other prefrontally encoded behavior, visuospatial discrimination, and found that it was normal in AS model mice (Fig. 6). We chose visuospatial discrimination because, although it is not an extinction task, it models cognitive flexibility and because Fragile X model mice display both impaired visuospatial discrimination and enhanced extinction (Krueger et al., 2011). Although performance on a visuospatial discrimination task was normal in AS model mice, AS mice did show increased perseverative behavior while performing the task. Further work is needed to test a wider range of prefrontally encoded behaviors, including attentive processes, reward contingency, reversal learning, and transitive inference (Dalley et al., 2004; Silverman et al., 2015).

Overall, the robust decrease in operant responses during extinction training may provide a readout of prefrontal dysfunction in AS model mice. Extinction phenotypes are remarkably similar in form and in degree between mouse models of AS and Fragile X syndrome, suggesting that extinction has value as a behavioral measure in related neurodevelopmental disorders.

\section{References}

Allensworth M, Saha A, Reiter LT, Heck DH (2011) Normal social seeking behavior, hypoactivity and reduced exploratory range in a mouse model of angelman syndrome. BMC Genet 12:7. CrossRef Medline

Augur IF, Wyckoff AR, Aston-Jones G, Kalivas PW, Peters J (2016) Chemogenetic activation of an extinction neural circuit reduces cue-induced 
reinstatement of cocaine seeking. J Neurosci 36:10174-10180. CrossRef Medline

Bird LM (2014) Angelman syndrome: review of clinical and molecular aspects. Appl Clin Genet 7:93-104. CrossRef Medline

Born HA, Dao AT, Levine AT, Lee WL, Mehta NM, Mehra S, Weeber EJ, Anderson AE (2017) Strain-dependence of the angelman syndrome phenotypes in Ube3a maternal deficiency mice. Sci Rep 7:8451. CrossRef Medline

Bouton ME (2004) Context and behavioral processes in extinction. Learn Mem 11:485-494. CrossRef Medline

Bruinsma CF, Schonewille M, Gao Z, Aronica EM, Judson MC, Philpot BD, Hoebeek FE, van Woerden GM, De Zeeuw CI, Elgersma Y (2015) Dissociation of locomotor and cerebellar deficits in a murine angelman syndrome model. J Clin Invest 125:4305-4315. CrossRef Medline

Cea-Del Rio CA, Huntsman MM (2014) The contribution of inhibitory interneurons to circuit dysfunction in fragile X syndrome. Front Cell Neurosci 8:245. CrossRef Medline

Chan CKJ, Harris JA (2017) Extinction of pavlovian conditioning: the influence of trial number and reinforcement history. Behav Processes 141: 19-25. CrossRef Medline

Cho JH, Deisseroth K, Bolshakov VY (2013) Synaptic encoding of fear extinction in mPFC-amygdala circuits. Neuron 80:1491-1507. CrossRef Medline

Criado-Marrero M, Santini E, Porter JT (2014) Modulating fear extinction memory by manipulating SK potassium channels in the infralimbic cortex. Front Behav Neurosci 8:96. CrossRef Medline

Cruz E, López AV, Porter JT (2014) Spontaneous recovery of fear reverses extinction-induced excitability of infralimbic neurons. PLoS One 9:e103596. CrossRef Medline

Dalley JW, Cardinal RN, Robbins TW (2004) Prefrontal executive and cognitive functions in rodents: neural and neurochemical substrates. Neurosci Biobehav Rev 28:771-784. CrossRef Medline

de Carvalho Myskiw J, Furini CR, Schmidt B, Ferreira F, Izquierdo I (2015) Extinction learning, which consists of the inhibition of retrieval, can be learned without retrieval. Proc Natl Acad Sci U S A 112:E230-E233. CrossRef Medline

Dölen G, Osterweil E, Rao BS, Smith GB, Auerbach BD, Chattarji S, Bear MF (2007) Correction of fragile X syndrome in mice. Neuron 56:955-962. CrossRef Medline

Do-Monte FH, Manzano-Nieves G, Quiñones-Laracuente K, Ramos-Medina L, Quirk GJ (2015) Revisiting the role of infralimbic cortex in fear extinction with optogenetics. J Neurosci 35:3607-3615. CrossRef Medline

Gao FF, Lv JW, Wang Y, Fan R, Li Q, Zhang Z, Wei L (2016) Tamoxifen induces hepatotoxicity and changes to hepatocyte morphology at the early stage of endocrinotherapy in mice. Biomed Rep 4:102-106. CrossRef Medline

Hayashi S, McMahon AP (2002) Efficient recombination in diverse tissues by a tamoxifen-inducible form of cre: a tool for temporally regulated gene activation/inactivation in the mouse. Dev Biol 244:305-318. CrossRef Medline

Heck DH, Zhao Y, Roy S, LeDoux MS, Reiter LT (2008) Analysis of cerebellar function in Ube3a-deficient mice reveals novel genotype-specific behaviors. Hum Mol Genet 17:2181-2189. CrossRef Medline

Herry C, Vouimba RM, Garcia R (1999) Plasticity in the mediodorsal thalamo-prefrontal cortical transmission in behaving mice. J Neurophysiol 82:2827-2832. CrossRef Medline

Huang HS, Burns AJ, Nonneman RJ, Baker LK, Riddick NV, Nikolova VD, Riday TT, Yashiro K, Philpot BD, Moy SS (2013) Behavioral deficits in an Angelman syndrome model: effects of genetic background and age. Behav Brain Res 243:79-90. CrossRef Medline

Huh WJ, Khurana SS, Geahlen JH, Kohli K, Waller RA, Mills JC (2012) Tamoxifen induces rapid, reversible atrophy, and metaplasia in mouse stomach. Gastroenterology 142:21-24.e7. CrossRef Medline

Jamal I, Kumar V, Vatsa N, Singh BK, Shekhar S, Sharma A, Jana NR (2017) Environmental enrichment improves behavioral abnormalities in a mouse model of Angelman syndrome. Mol Neurobiol 54:5319-5326. CrossRef Medline

Jiang YH, Armstrong D, Albrecht U, Atkins CM, Noebels JL, Eichele G, Sweatt JD, Beaudet AL (1998) Mutation of the Angelman ubiquitin ligase in mice causes increased cytoplasmic p53 and deficits of contextual learning and long-term potentiation. Neuron 21:799-811. CrossRef Medline

Judson MC, Wallace ML, Sidorov MS, Burette AC, Gu B, van Woerden GM,
King IF, Han JE, Zylka MJ, Elgersma Y, Weinberg RJ, Philpot BD (2016) GABAergic neuron-specific loss of Ube3a causes Angelman syndromelike EEG abnormalities and enhances seizure susceptibility. Neuron 90: 56-69. CrossRef Medline

Judson MC, Burette AC, Thaxton CL, Pribisko AL, Shen MD, Rumple AM, Del Cid WA, Paniagua B, Styner M, Weinberg RJ, Philpot BD (2017) Decreased axon caliber underlies loss of fiber tract integrity, disproportional reductions in white matter volume, and microcephaly in Angelman syndrome model mice. J Neurosci 37:7347-7361. CrossRef Medline

Kaplan GB, Heinrichs SC, Carey RJ (2011) Treatment of addiction and anxiety using extinction approaches: neural mechanisms and their treatment implications. Pharmacol Biochem Behav 97:619-625. CrossRef Medline

Kim HS, Cho HY, Augustine GJ, Han JH (2016) Selective control of fear expression by optogenetic manipulation of infralimbic cortex after extinction. Neuropsychopharmacology 41:1261-1273. CrossRef Medline

Kishino T, Lalande M, Wagstaff J (1997) UBE3A/E6-AP mutations cause Angelman syndrome. Nat Genet 15:70-73. CrossRef Medline

Knapska E, Maren S (2009) Reciprocal patterns of c-fos expression in the medial prefrontal cortex and amygdala after extinction and renewal of conditioned fear. Learn Mem 16:486-493. CrossRef Medline

Krueger DD, Osterweil EK, Chen SP, Tye LD, Bear MF (2011) Cognitive dysfunction and prefrontal synaptic abnormalities in a mouse model of fragile X syndrome. Proc Natl Acad Sci U S A 108:2587-2592. CrossRef Medline

LaLumiere RT, Niehoff KE, Kalivas PW (2010) The infralimbic cortex regulates the consolidation of extinction after cocaine self-administration. Learn Mem 17:168-175. CrossRef Medline

LaSalle JM, Reiter LT, Chamberlain SJ (2015) Epigenetic regulation of UBE3A and roles in human neurodevelopmental disorders. Epigenomics 7:1213-1228. CrossRef Medline

Laurent V, Westbrook RF (2009) Inactivation of the infralimbic but not the prelimbic cortex impairs consolidation and retrieval of fear extinction. Learn Mem 16:520-529. CrossRef Medline

Lonard DM, Smith CL (2002) Molecular perspectives on selective estrogen receptor modulators (SERMs): progress in understanding their tissuespecific agonist and antagonist actions. Steroids 67:15-24. CrossRef Medline

Mackintosh NJ (1974) The psychology of animal learning. London; New York, NY: Academic.

Mandel-Brehm C, Salogiannis J, Dhamne SC, Rotenberg A, Greenberg ME (2015) Seizure-like activity in a juvenile Angelman syndrome mouse model is attenuated by reducing arc expression. Proc Natl Acad Sci U S A 112:5129-5134. CrossRef Medline

Marchant NJ, Furlong TM, McNally GP (2010) Medial dorsal hypothalamus mediates the inhibition of reward seeking after extinction. J Neurosci 30:14102-14115. CrossRef Medline

Milad MR, Quirk GJ (2002) Neurons in medial prefrontal cortex signal memory for fear extinction. Nature 420:70-74. CrossRef Medline

Millan EZ, Marchant NJ, McNally GP (2011) Extinction of drug seeking. Behav Brain Res 217:454-462. CrossRef Medline

Miura K, Kishino T, Li E, Webber H, Dikkes P, Holmes GL, Wagstaff J (2002) Neurobehavioral and electroencephalographic abnormalities in Ube3a maternal-deficient mice. Neurobiol Dis 9:149-159. CrossRef Medline

Morgan MA, Romanski LM, LeDoux JE (1993) Extinction of emotional learning: contribution of medial prefrontal cortex. Neurosci Lett 163: 109-113. CrossRef Medline

Nelson SB, Valakh V (2015) Excitatory/inhibitory balance and circuit homeostasis in autism spectrum disorders. Neuron 87:684-698. CrossRef Medline

O’Hearn K, Asato M, Ordaz S, Luna B (2008) Neurodevelopment and executive function in autism. Dev Psychopathol 20:1103-1132. CrossRef Medline

Ovari J, Leri F (2008) Inactivation of the ventromedial prefrontal cortex mimics re-emergence of heroin seeking caused by heroin reconditioning. Neurosci Lett 444:52-55. CrossRef Medline

Peters J, LaLumiere RT, Kalivas PW (2008) Infralimbic prefrontal cortex is responsible for inhibiting cocaine seeking in extinguished rats. J Neurosci 28:6046-6053. CrossRef Medline

Peters J, Kalivas PW, Quirk GJ (2009) Extinction circuits for fear and addiction overlap in prefrontal cortex. Learn Mem 16:279-288. CrossRef Medline

Philpot BD, Espinosa JS, Bear MF (2003) Evidence for altered NMDA receptor function as a basis for metaplasticity in visual cortex. J Neurosci 23:5583-5588. Medline 
Quirk GJ, Russo GK, Barron JL, Lebron K (2000) The role of ventromedial prefrontal cortex in the recovery of extinguished fear. J Neurosci 20:62256231. Medline

Radwan B, Dvorak D, Fenton AA (2016) Impaired cognitive discrimination and discoordination of coupled theta-gamma oscillations in Fmr1 knockout mice. Neurobiol Dis 88:125-138. CrossRef Medline

Sah P, Faber ES (2002) Channels underlying neuronal calcium-activated potassium currents. Prog Neurobiol 66:345-353. CrossRef Medline

Santini E, Ge H, Ren K, Peña de Ortiz S, Quirk GJ (2004) Consolidation of fear extinction requires protein synthesis in the medial prefrontal cortex. J Neurosci 24:5704-5710. CrossRef Medline

Santini E, Quirk GJ, Porter JT (2008) Fear conditioning and extinction differentially modify the intrinsic excitability of infralimbic neurons. J Neurosci 28:4028-4036. CrossRef Medline

Schneider A, Hagerman RJ, Hessl D (2009) Fragile X syndrome: from genes to cognition. Dev Disabil Res Rev 15:333-342. CrossRef Medline

Sell GL, Margolis SS (2015) From UBE3A to angelman syndrome: a substrate perspective. Front Neurosci 9:322. CrossRef Medline

Sidorov MS, Krueger DD, Taylor M, Gisin E, Osterweil EK, Bear MF (2014) Extinction of an instrumental response: a cognitive behavioral assay in Fmr1 knockout mice. Genes Brain Behav 13:451-458. CrossRef Medline

Sidorov MS, Deck GM, Dolatshahi M, Thibert RL, Bird LM, Chu CJ, Philpot BD (2017) Delta rhythmicity is a reliable EEG biomarker in Angelman syndrome: a parallel mouse and human analysis. J Neurodev Disord 9:17. CrossRef Medline

Siegel JJ, Chitwood RA, Ding JM, Payne C, Taylor W, Gray R, Zemelman BV, Johnston D (2017) Prefrontal cortex dysfunction in Fragile X mice depends on the continued absence of Fragile $\mathrm{X}$ mental retardation protein in the adult brain. J Neurosci 37:7305-7317. CrossRef Medline

Sierra-Mercado D Jr, Corcoran KA, Lebrón-Milad K, Quirk GJ (2006) Inactivation of the ventromedial prefrontal cortex reduces expression of conditioned fear and impairs subsequent recall of extinction. Eur J Neurosci 24:1751-1758. CrossRef Medline

Silva-Santos S, van Woerden GM, Bruinsma CF, Mientjes E, Jolfaei MA, Distel B, Kushner SA, Elgersma Y (2015) Ube3a reinstatement identifies distinct developmental windows in a murine Angelman syndrome model. J Clin Invest 125:2069-2076. CrossRef Medline

Silverman JL, Gastrell PT, Karras MN, Solomon M, Crawley JN (2015) Cognitive abilities on transitive inference using a novel touchscreen technology for mice. Cereb Cortex 25:1133-1142. CrossRef Medline

Sparta DR, Hovelsø N, Mason AO, Kantak PA, Ung RL, Decot HK, Stuber GD (2014) Activation of prefrontal cortical parvalbumin interneurons facilitates extinction of reward-seeking behavior. J Neurosci 34:3699-3705. CrossRef Medline

Stoppel DC, Anderson MP (2017) Hypersociability in the Angelman syndrome mouse model. Exp Neurol 293:137-143. CrossRef Medline

Sun J, Zhu G, Liu Y, Standley S, Ji A, Tunuguntla R, Wang Y, Claus C, Luo Y, Baudry M, Bi X (2015) UBE3A regulates synaptic plasticity and learning and memory by controlling SK2 channel endocytosis. Cell Rep 12:449461. CrossRef Medline

Thibert RL, Larson AM, Hsieh DT, Raby AR, Thiele EA (2013) Neurologic manifestations of Angelman syndrome. Pediatr Neurol 48:271-279. CrossRef Medline

van Woerden GM, Harris KD, Hojjati MR, Gustin RM, Qiu S, de Avila Freire R, Jiang YH, Elgersma Y, Weeber EJ (2007) Rescue of neurological deficits in a mouse model for Angelman syndrome by reduction of $\alpha$ CaMKII inhibitory phosphorylation. Nat Neurosci 10:280-282. CrossRef Medline

VanElzakker MB, Dahlgren MK, Davis FC, Dubois S, Shin LM (2014) From Pavlov to PTSD: the extinction of conditioned fear in rodents, humans, and anxiety disorders. Neurobiol Learn Mem 113:3-18. CrossRef Medline

Wallace ML, Burette AC, Weinberg RJ, Philpot BD (2012) Maternal loss of Ube3a produces an excitatory/inhibitory imbalance through neuron type-specific synaptic defects. Neuron 74:793-800. CrossRef Medline

Yashiro K, Riday TT, Condon KH, Roberts AC, Bernardo DR, Prakash R, Weinberg RJ, Ehlers MD, Philpot BD (2009) Ube3a is required for experience-dependent maturation of the neocortex. Nat Neurosci 12: 777-783. CrossRef Medline

Yuan P, Raz N (2014) Prefrontal cortex and executive functions in healthy adults: a meta-analysis of structural neuroimaging studies. Neurosci Biobehav Rev 42:180-192. CrossRef Medline 